\title{
SJRM \\ The evaluation of retinoic acid and estrogen on mouse induced pluripotent stem cells differentiation into female germ cells
}

\author{
ARTICLE INFO \\ Article Type \\ Original Research

\section{Authors} \\ Javad Amini Mahabadi 1,2, (iD PhD \\ Hossein Nikzad ${ }^{3}$, iD $\mathrm{PhD}^{*}$ \\ Hassan Hassani Bafrani ${ }^{4}, \mathrm{PhD}$ \\ Zahra Karami ${ }^{5}$, iD MSc \\ Vajihe Taghdiri Nooshabadi ${ }^{6}$, iD $\mathrm{PhD}$ \\ ${ }^{1}$ Sarem Fertility and Infertility Research \\ Center (SAFIR), Sarem Women's Hospital, \\ Iran University of Medical Sciences \\ (IUMS), Tehran, Iran. \\ $\mathrm{PhD}$ of reproductive biology, \\ Gametogenesis Research Center, Kashan \\ University of Medical Sciences, Kashan, \\ Iran. \\ 3 Full professor of Anatomical science, \\ Gametogenesis Research Center, Kashan \\ University of Medical Sciences, Kashan, \\ Iran \\ 4 Associate professor of Anatomical \\ science, Gametogenesis Research Center, \\ Kashan University of Medical Sciences, \\ Kashan, Iran \\ $5 \mathrm{PhD}$ Student of developmental biology, \\ Department of Biology, Karaj Branch, \\ Islamic Azad University, Karaj, Iran. \\ 6 Assistant Professor of tissue engineering \\ and applied cell science, Nervous System \\ Stem Cells Research Center, Semnan \\ University of Medical Sciences, Semnan, \\ Iran. Department of Tissue Engineering and \\ Applied Cell Sciences, School of Medicine, \\ Semnan University of Medical Science, \\ Semnan, Iran.
}

\section{*Corresponding Author}

Address: Ghotb Ravandi boulevard, Kashan University of Medical Sciences, Kashan, I.R. Iran. Phone: +98 9131616689 \& +98155621158

hosseinnikzad43@yahoo.com; nikzad_h@kaums.ac.i

Article History

Received: April 24, 2020

Accepted: May 25, 2020

e Published: January 14, 2021

\section{ABSTRACT}

Aims: The use of stem cells has been able to treat patients with genetic and induced abnormalities and diseases such as non-obstructive azoospermia. Today, more attention has been paid to self-induced induced pluripotent stem cells (iPSCs). The aim of this study was to investigate the role of estrogen with retinoic acid on the differentiation of mouse iPSCs towards female germ cells.

Methods: In this study, mouse embryonic fibroblast cells were extracted as feeding cells and inactivated. The target groups were adjusted for estrogen with retinoic acid at intervals of days 0, 4 and 7. Expression of these genes was performed by Real Time PCR technique.

Results: In this study, the expression of genes such as Stra8, Stella, Ddx4 and GDF9 was evaluated. Real-time data showed that the expression of these genes increased in estrogen group on day 4 of embryoid bodies culture, while the differences were not significant on other days.

Conclusion: It is very difficult to control the differentiation of mouse induced pluripotent stem cells (miPSCs) and the role of estrogen was carefully investigated in vitro in this study. Evidence suggests that female germ cells can differentiate from miPSCs in vitro. Treatment of cells with estrogen showed a greater effect on the differentiation process on day 4.

Keywords: Differentiation; Mouse induced pluripotent stem cells; Female germ cells; Estrogen; Retinoic Acid.

Copyright(C) 2021, ASP Ins. This open-access article is published under the terms of the Creative Commons Attribution-Noncommercial 4.0 International License which permits Share (copy and distribute the material in any medium or format) and Adapt (remix, transform, and build 
رتينوئيك اسيد و در بازه هاى زمانى روزهاى صفر، بأ و V تنظيم شد. بيان رن هاى مورد نظر با تكنيك Real Time PCR انجام شد.

يافته ها: در اين مطالعه، بيان زن هايى از قبيل Stra8، Stella

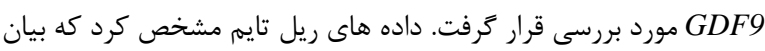

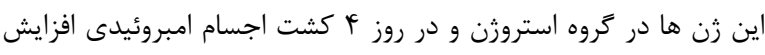

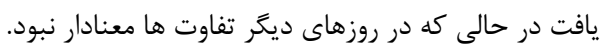

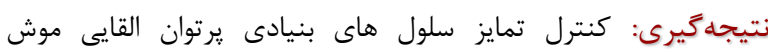

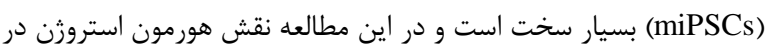

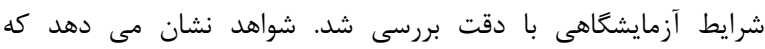

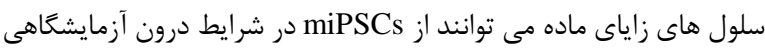

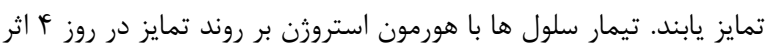
بيشترى را از خود نشان داد.

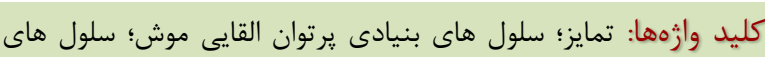
زاياى ماده؛ استروزن؛ رتينوئيك اسيد.

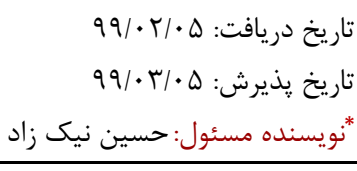

مقدمه

بسيارى از زوجين داراى مشكلات نابارورى با عوامل محيطى و رنتيكى روبرو

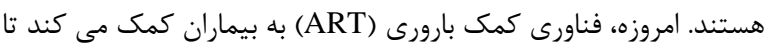

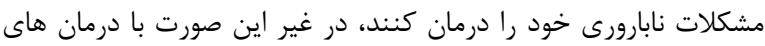

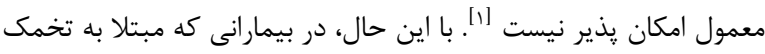

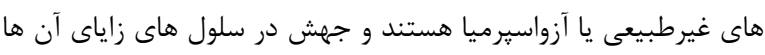

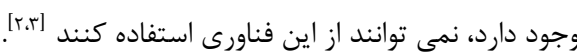

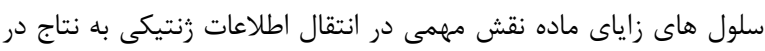

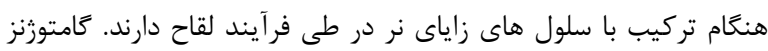

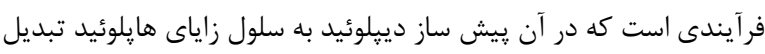

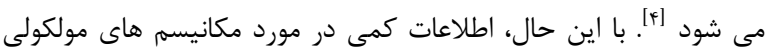

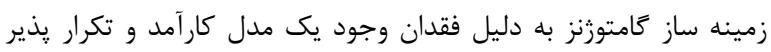
براى اين فرآيند وجود دارد.

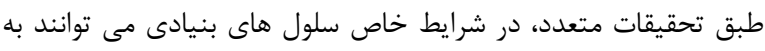

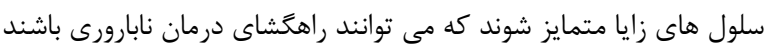

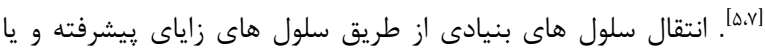

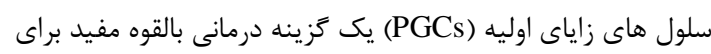

\section{بررسى اثر رتينوئيك اسيد و و} استروزن بر تمايز سلول هاى بنيادى

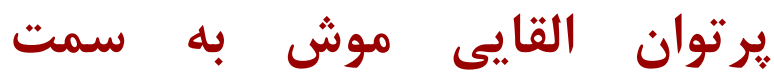
سلول هاى زاياى ماده

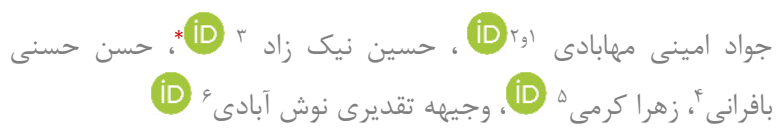
' مركز تحقيقات بارورى و نابارورى صارم، بيمارستان فوق تخصصى صارم، دانشگاه علوم يزشكى ايران، تهران، ايران.

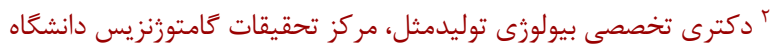
علوم يزشكى كاشان، كاشان، ايران.

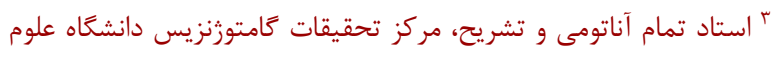

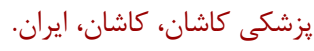

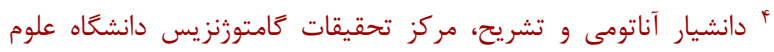
يز شكى كاشان، كاشان، ايران.

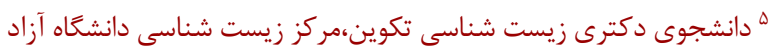

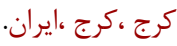
` استاديار مهندسى بران بافت و علوم سلولى - كاربردى، مركز تحقيقات

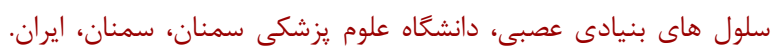

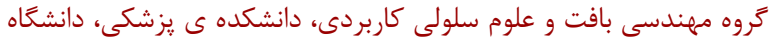
علوم يزشكى سمنان، سمنان، ايران.

جكيده

اهداف: : استفاده از سلول هاى بنيادى توانسته است بيمارانى كه دجار

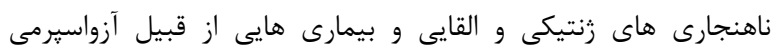

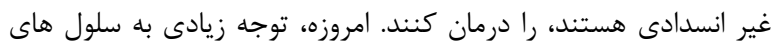

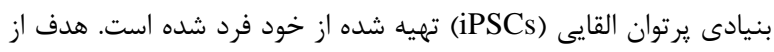

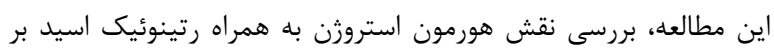

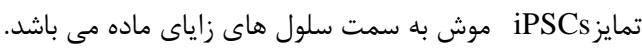

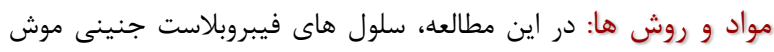

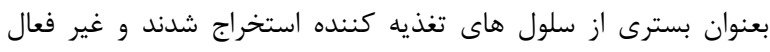

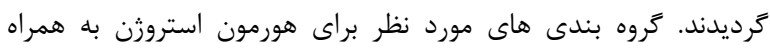




\section{استخراج و غير فعال سازى سلول هاى فيبروبلاست جنين

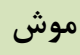

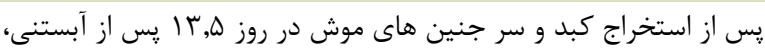

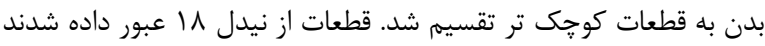

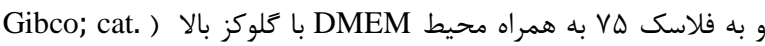

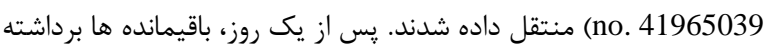

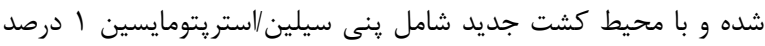
(Pen/Strep; Gibco; cat. no. 15140-148)

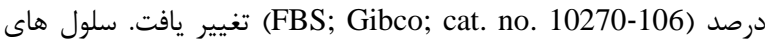

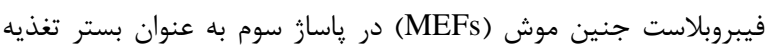
كننده به كار كرفته شدند. سيس، براى غيس غيرفعال كردن اين سلول ها، مقدار

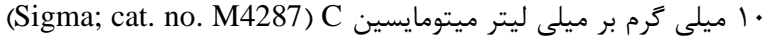
در محيط DMEM/F12 استفاده كرديد (شكل ل (1).

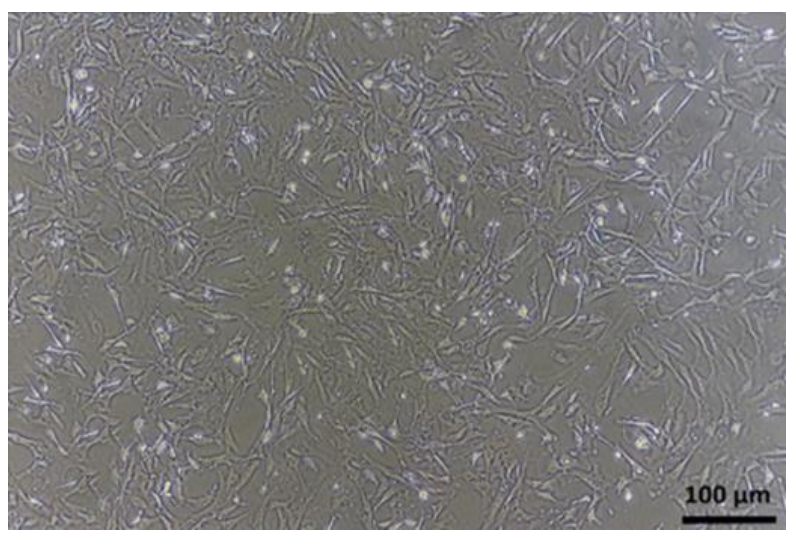

شكل ا: سلول هاى فيبروبالاست جنين موش به عنوان بستر تنذيه كننده

\section{كسترش سلول هاى بنيادى ير توان القايى موش}

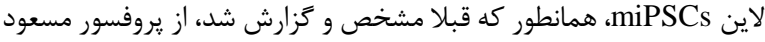

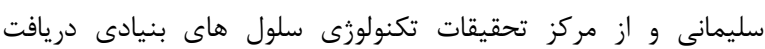

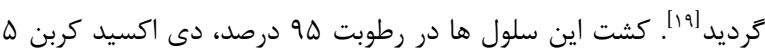

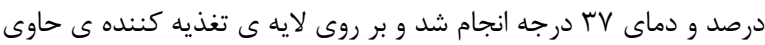

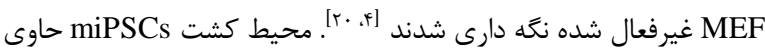

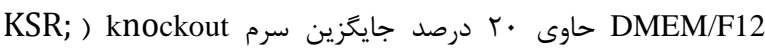

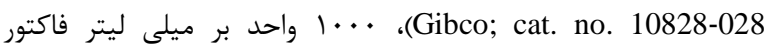

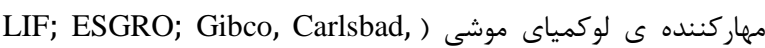
Gibco; ) (CA; cat. no. ESG1107

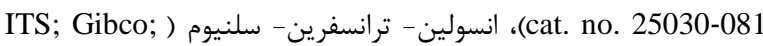

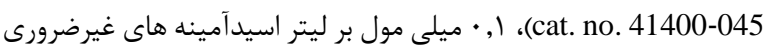

بازكرداندن نابارورى است كه هيءج توجيه زنتيكى ندارد [ـ]. اخيراً،

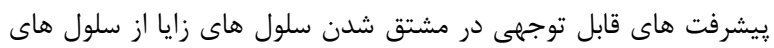

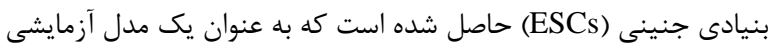

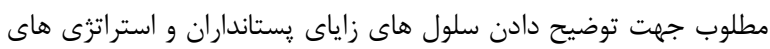

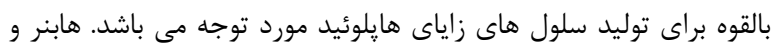

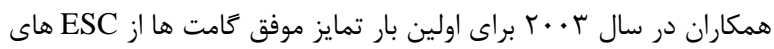

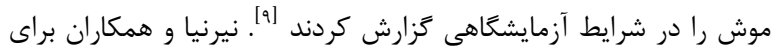

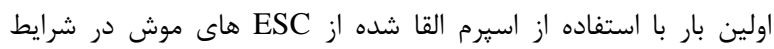

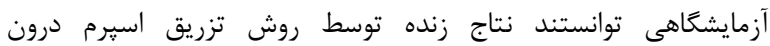

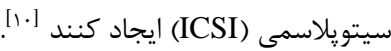

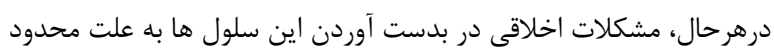

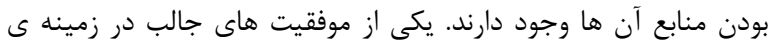

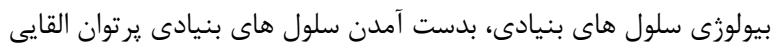

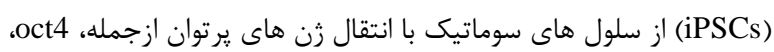

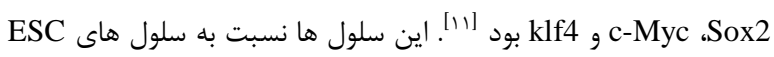

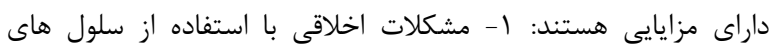

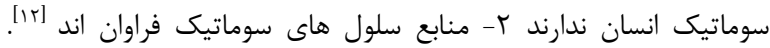

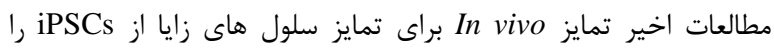

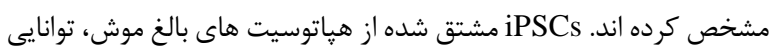

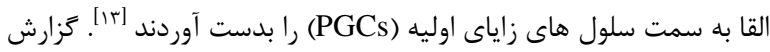

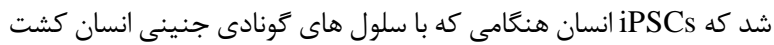

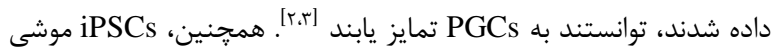

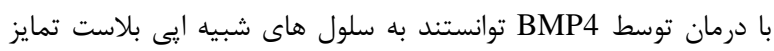

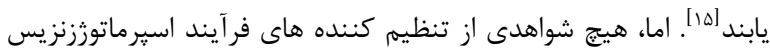

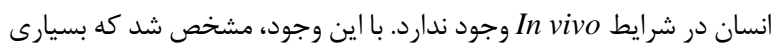

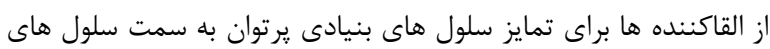

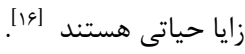
يكى از مشتقات ويتامين A رتينوئيك اسيد است كه نقش مههمى در تمايز

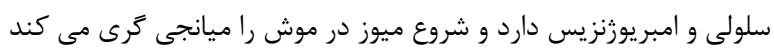

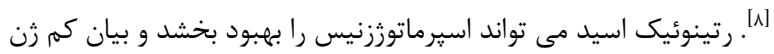

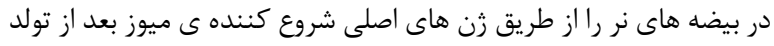

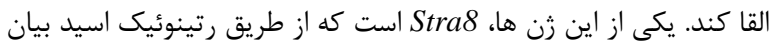

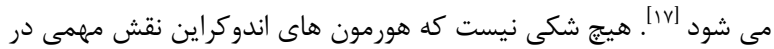

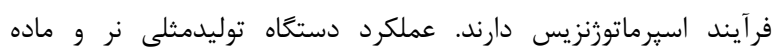

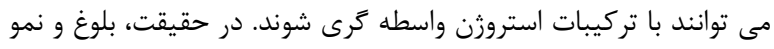

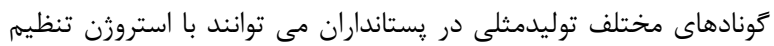

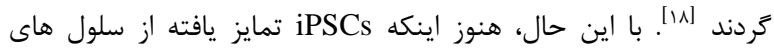

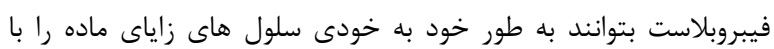

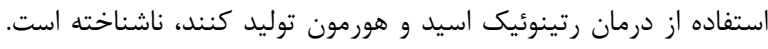
بنابراين، هدف از مطالعه ى حاضر، بررسى اثر رتينوئيك اسيد و استروزن أنئن

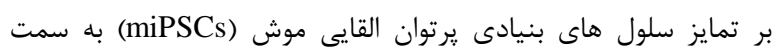

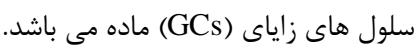


ا, • درصد آماده شدند و EBs به يليت هاى آماده منتقل ترديدند. براى

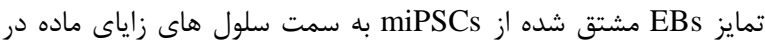

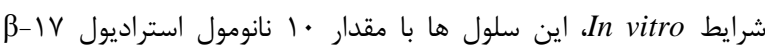

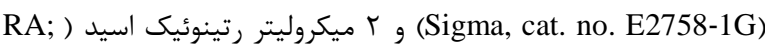

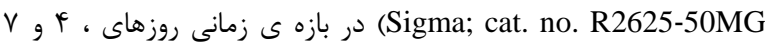

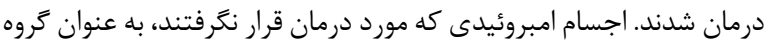
كنترل در نظر گرفته شدند.

\section{ستخراج RNA، سنتز CDNA و Real Time PCR}

براى استخراج RNA از سلول هاى برداشت شده از كيت ترايزول (Invitrogen; cat. no. 15596026)

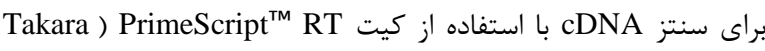

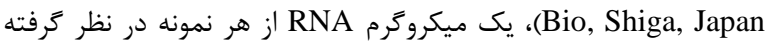
شد. تكنيك qPCR) Real Time PCR براى بيان كمى زن هاى از قبيل:

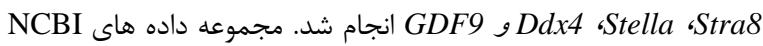

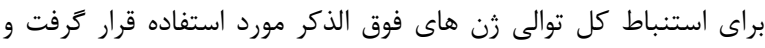

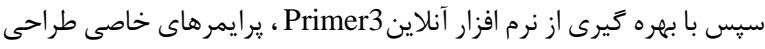

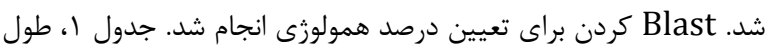

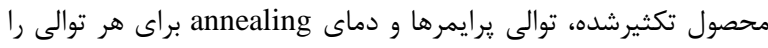

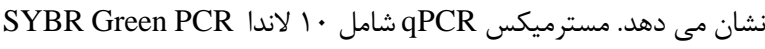
نDNA Master Mix Buffer

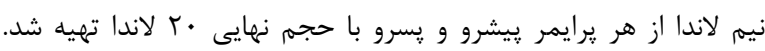

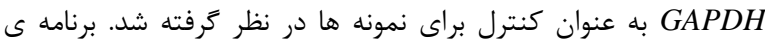

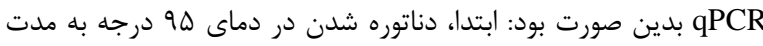

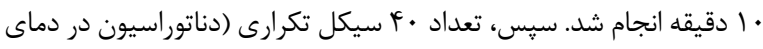

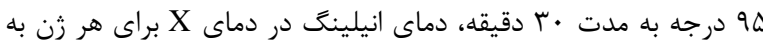

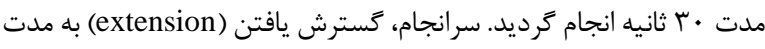

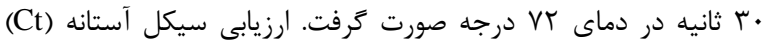

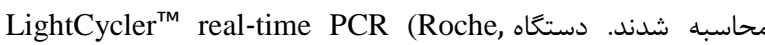
براى واكنش هاى qPCR در سه تكرار استفاده شد.

\begin{tabular}{|c|c|c|c|c|}
\hline Gene & Forward sequence $\left(5^{>}>3^{\prime}\right)$ & Reverse sequence $\left(5^{\prime}>3^{\prime}\right)$ & $\begin{array}{l}\text { Fragment } \\
\text { size(bp) }\end{array}$ & $\begin{array}{l}\text { Annealing } \\
\text { Temperatur } \\
\text { "co }\end{array}$ \\
\hline Stras & GAAGTGCCTGGAGACCTTTG & $\begin{array}{l}\text { TGGAAGCAGCCTTTCT } \\
\text { CAAT }\end{array}$ & 150 & 59.7 \\
\hline Stella & TGAGAAGACTTGTTCGGATTGAG & $\begin{array}{l}\text { AGTTAAGATTTCCCA } \\
\text { GCACCAG }\end{array}$ & 256 & 57.5 \\
\hline Ddx4 & CTTCAGTAGCAGCACAAGAGG & $\begin{array}{c}\text { GGAGGAAGAACAGAA } \\
\text { GAACAGG }\end{array}$ & 267 & 57.5 \\
\hline GDF9 & AAAGAAGACTGGCACGAGGA & $\begin{array}{l}\text { CTGCAGCTTAGGGGT } \\
\text { CTCAC }\end{array}$ & 289 & 59.6 \\
\hline GAPDH & AACTTTGGCATTGTGGAAGG & $\begin{array}{l}\text { ACACATTGGGGGTAG } \\
\text { GAACA }\end{array}$ & 223 & 57.5 \\
\hline
\end{tabular}

جدول ا: يرايمرهاى طراحى شده براى آناليز توسط تكنيك Real Time PCR و رن ها در مراحل متفاوت تمايزى
ROCK inhibitor , (NEAA; Gibco; cat. no. 11140-035) (فقط يكبار بعد از ذوب (Sigma; cat. no. Y0503-1 MG) Y-27632

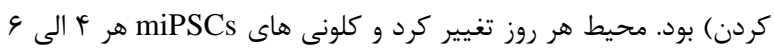

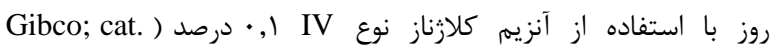

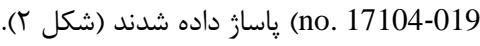
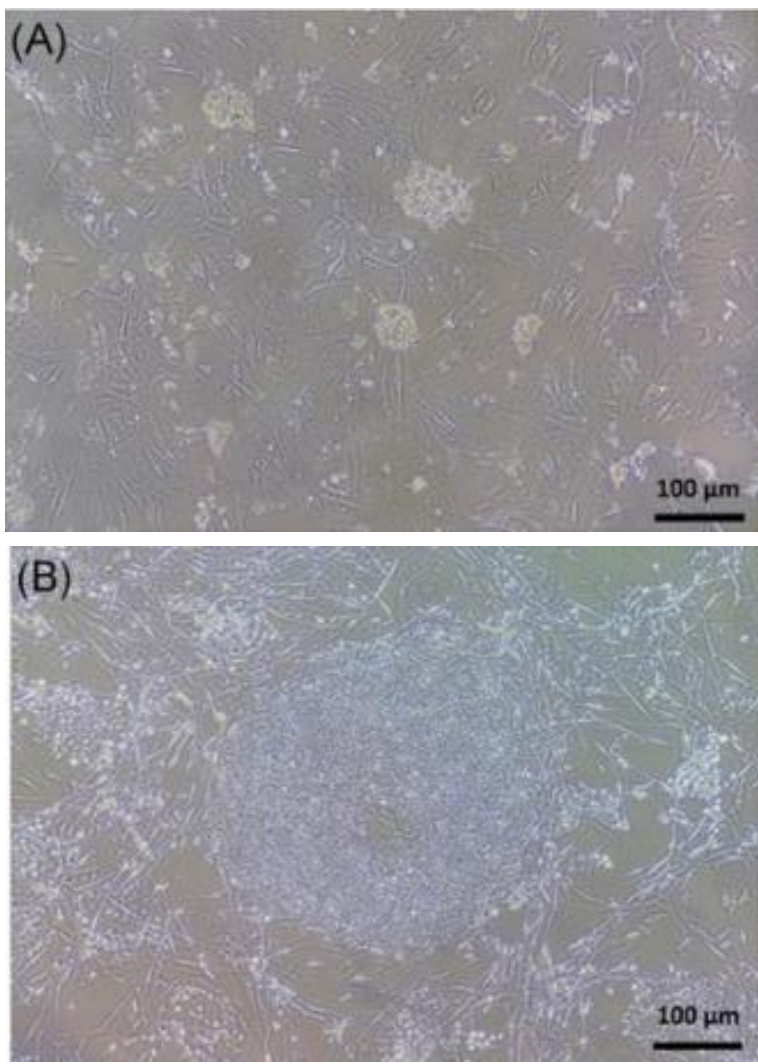

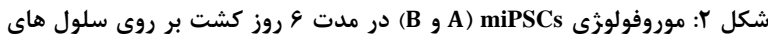
تغذيه كننده N MEF MEF, mouse embryonic fibroblast; miPSCs, mouse-induced pluripotent ) (stem cells

تمايز سلول هاى بنيادى برتوان القايى موش به سمت سلول هاى

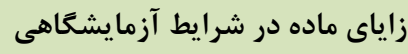

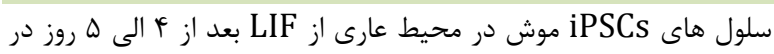

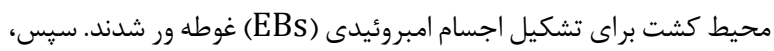

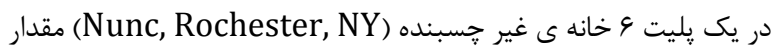

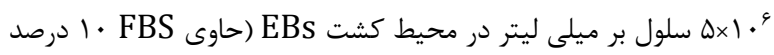

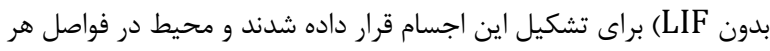

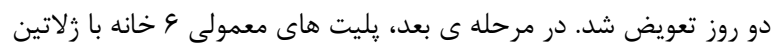


نشان دهنده فى فاز يس از ميوزى سلول هاست و بيان كننده ى سلول هاى

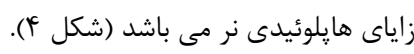

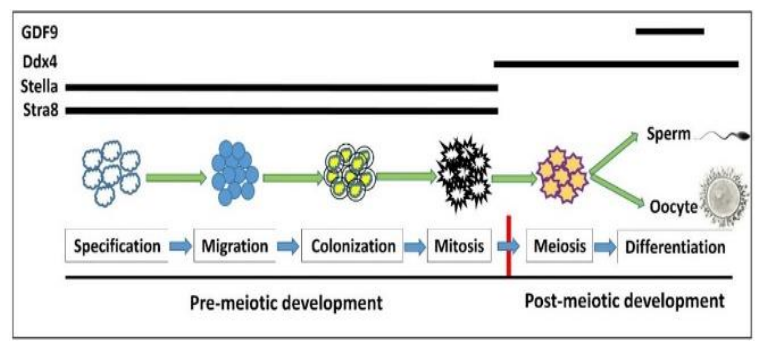

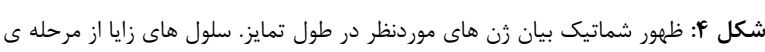

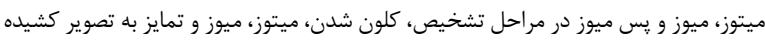

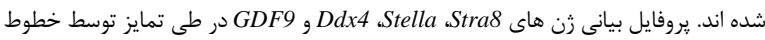
تيره رنَ مشخص گرديدند.

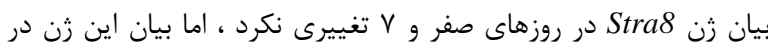

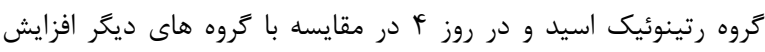

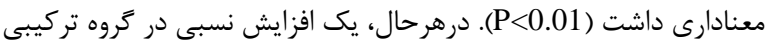

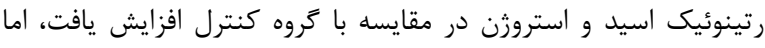

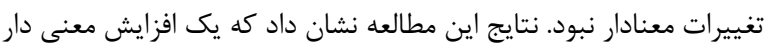

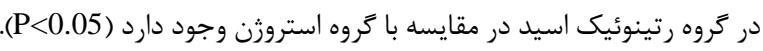

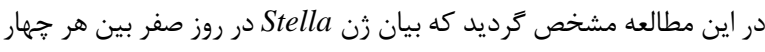

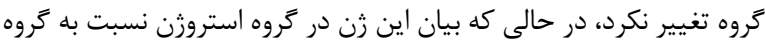

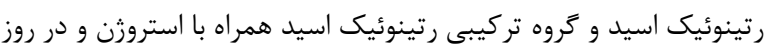

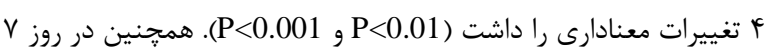

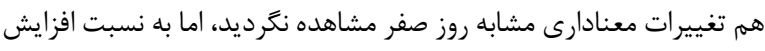

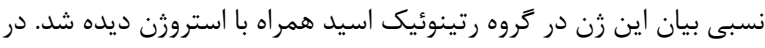

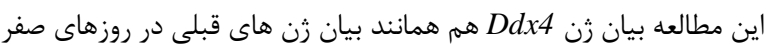

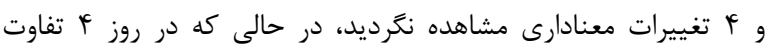

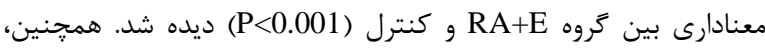
تفاوت معنادارى بين گروه هاى RA+E و كروه هاى RA

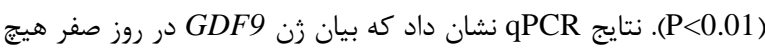

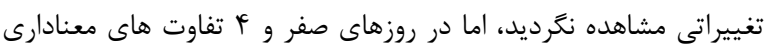

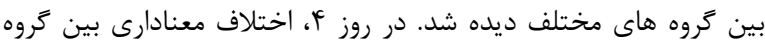
RA+E RA+E

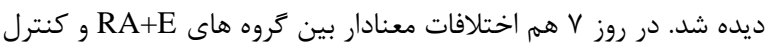
(P<0.001) ملاحظه كرديد و همين طور بين كروه كروه RA به ترتيب تفاوت معنى دارى (P<0.001) ديده شدرد مدرد

$$
\text { آناليز آمارى }
$$

تفاوت هاى معنادار بين گروه ها با استفاده از نرم افزار SPSS باريز

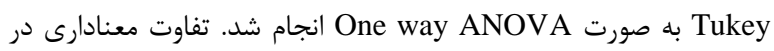
سطح P<0.05 در نظر كرفته شد.

بافته ها

شكل كيرى اجسام امبروئيدى هام

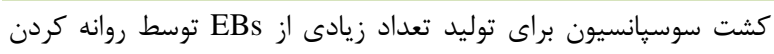
miPSCs

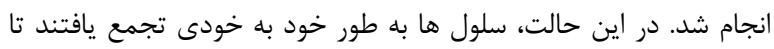

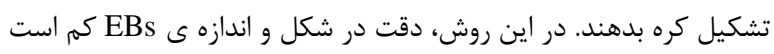

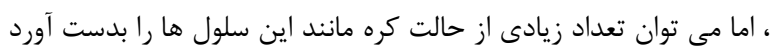

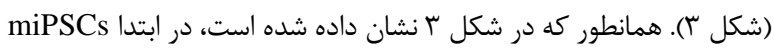

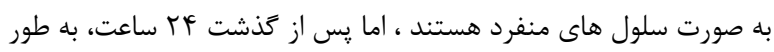

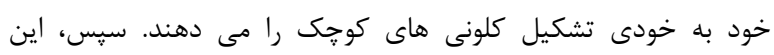

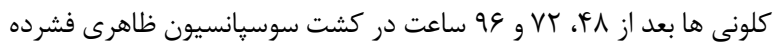
به خود مى كيرند.

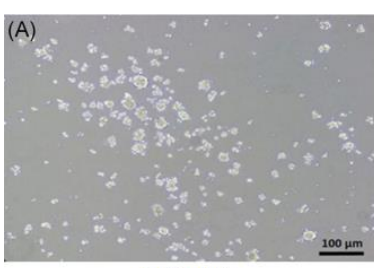

EB 1 Day

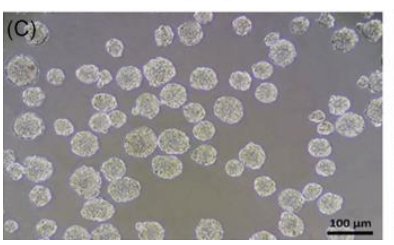

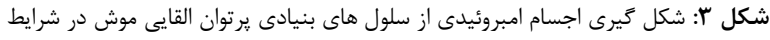
In vitro

يروفايل بيانى ثن هاى خاص سلول هاى زاياى ماده در تمايز اجسام امبروئيدى

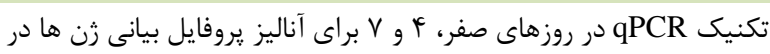

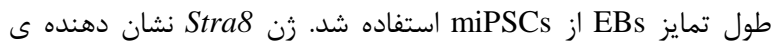

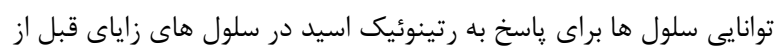

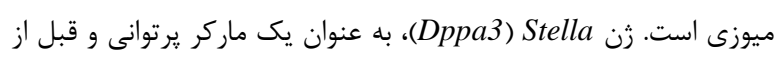
ميوزى در نظر ترفته مى شود. زن أن Sdx4 يك ماركر ميوزى است و 
زن Developmental Pluripotency يا DPA3) Stella In vivo در يك بازه ى زمانى مشخص بيان Associated 3

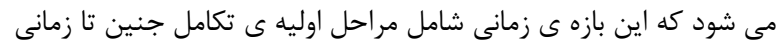

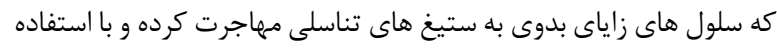

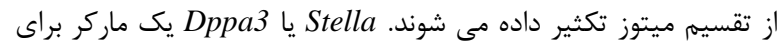

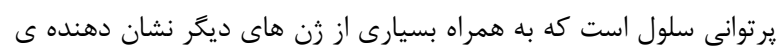

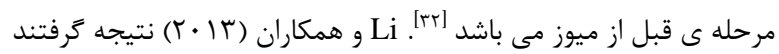

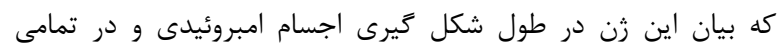

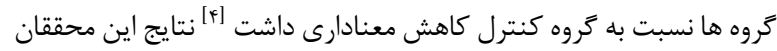

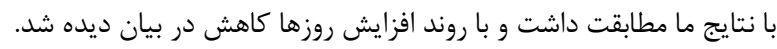
Eskandari

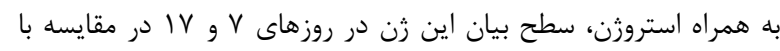

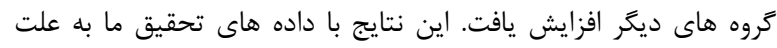

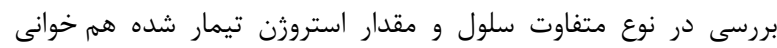

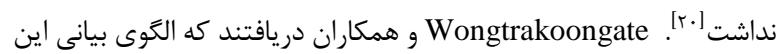

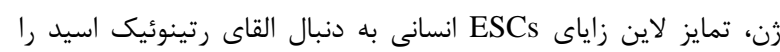

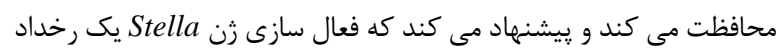

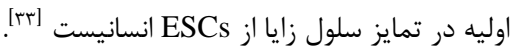

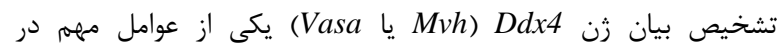
شكل كيرى EBs تمايز يافته از PGCs مي باشد. يافته هاى اين تحقيق نشان دادند كه بيان Ddx4 در كروه تركيبى رتينوئيك اسيد به همراه

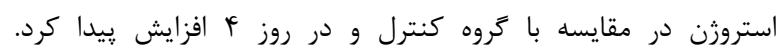
Eguizabal

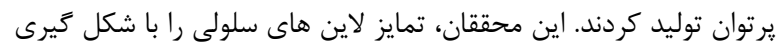

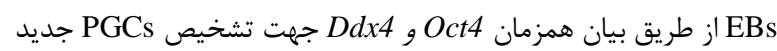

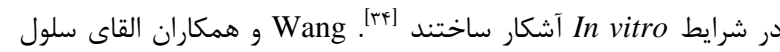

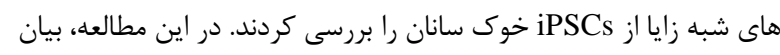

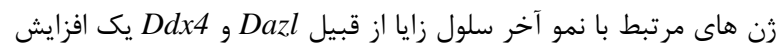

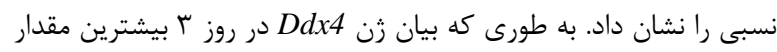

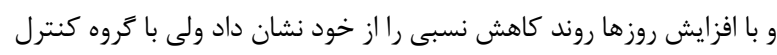

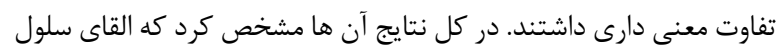

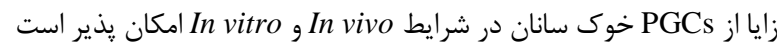

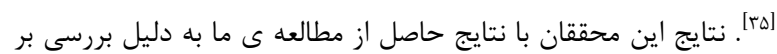
نوع حيوان متناقص مى باشد.

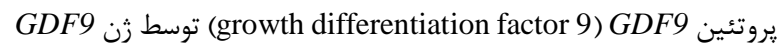
كد مى شود. اين يروتئين توسط سلول هاى سوماتيك تخمدان سنتز

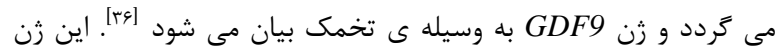
نقش كليدى در تكامل فوليكول هاى اوليه در تخمك داري دارد.

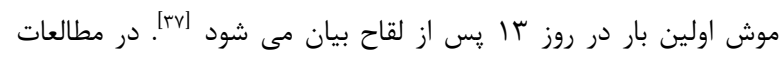

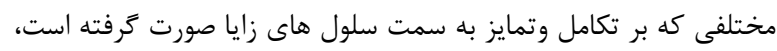

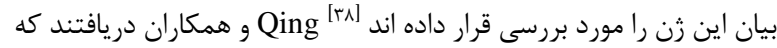

در خند دهل ى حذشته، مطالعات زيادى در زمينه ى توليد سلول هاى إى

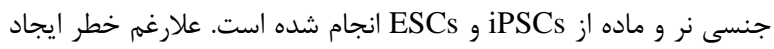

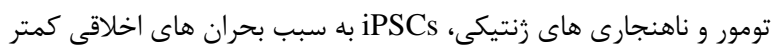

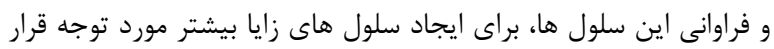

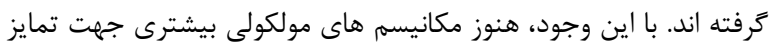

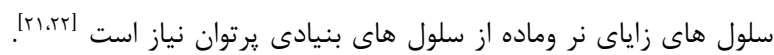

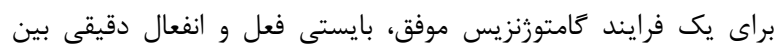

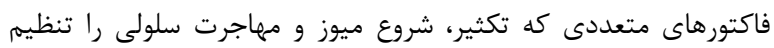

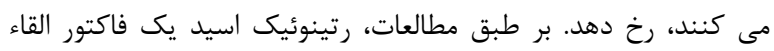

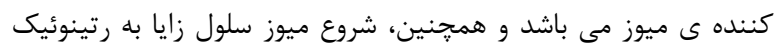

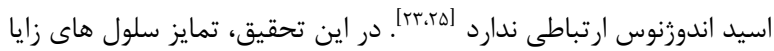

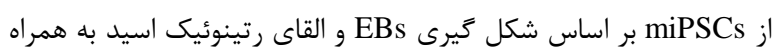

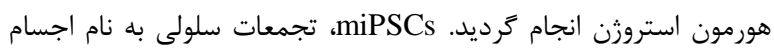

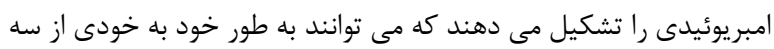

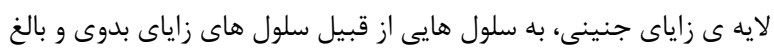

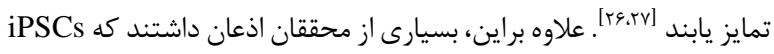

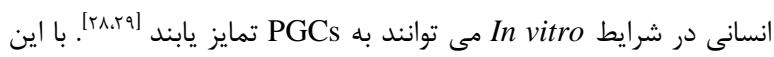

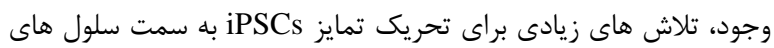

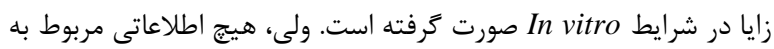

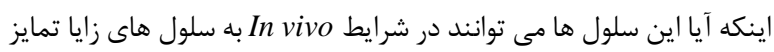

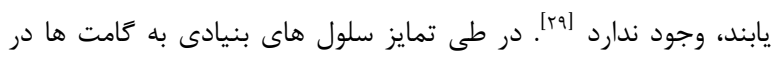

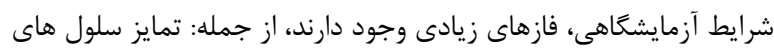

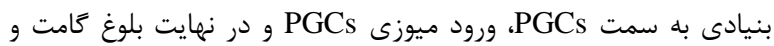

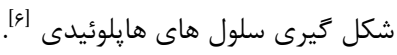

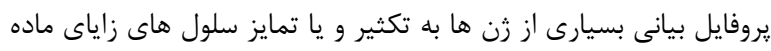

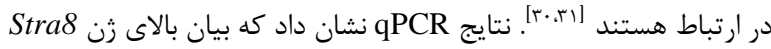
(Stimulated By Retinoic Acid 8)

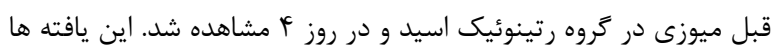

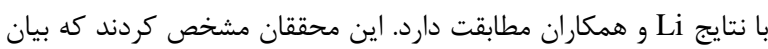

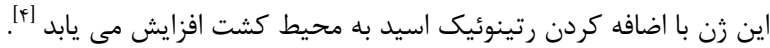

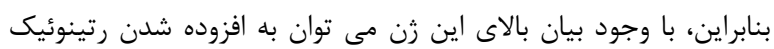

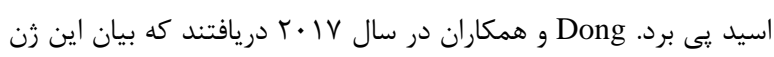

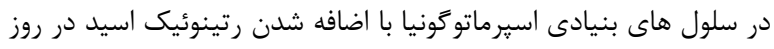

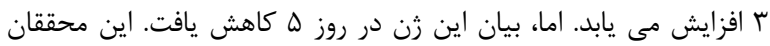

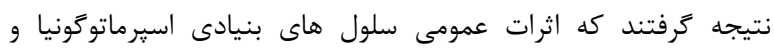

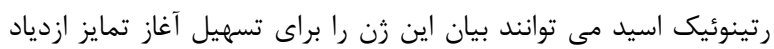

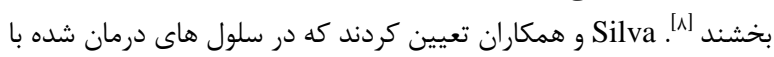

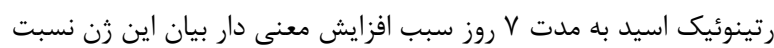

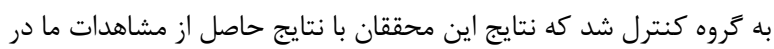

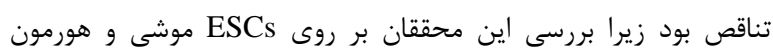

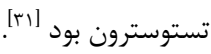


سهمه نويسند

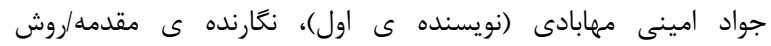

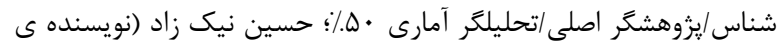

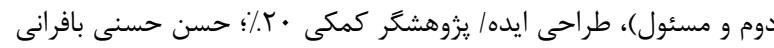

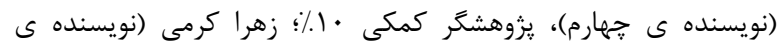

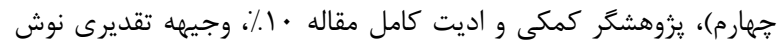

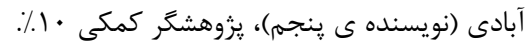

تاييديه اخلاقى:

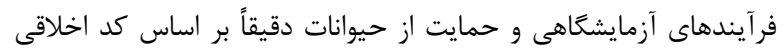

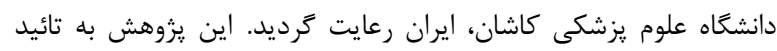

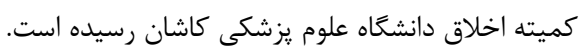

(IR.KAUMS.REC.1394.150)

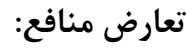 \\ در اين مطالعه تعارض منافع وجود نداشت.

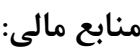 \\ توسط دانشكاه علوم يزشكى كاشان تامين شده است.
}

منابع:

1. Mahabadi JA, Tameh AA, Talaei SA, Karimian M, Rahiminia T, Enderami SE, et al. Retinoic acid and/or progesterone differentiate mouse induced pluripotent stem cells into male germ cells in vitro. J Cell Biochem. 2020;121(3):2159-69.

2. Li Y, Wang X, Feng X, Liao S, Zhang D, Cui $X$, et al. Generation of male germ cells from mouse induced pluripotent stem cells in vitro. Stem Cell Res. 2014;12(2):517-30.

3. Qiao J, Wang Z-B, Feng H-L, Miao Y-L, Wang $\mathrm{Q}, \mathrm{Yu} \mathrm{Y}$, et al. The root of reduced fertility in aged women and possible therapentic options: current status and future perspects. Mol Aspects Med. 2014;38:54-85.

4. Li P, Hu H, Yang S, Tian R, Zhang Z, Zhang $\mathrm{W}$, et al. Differentiation of induced pluripotent stem cells into male germ cells in vitro through embryoid body formation and

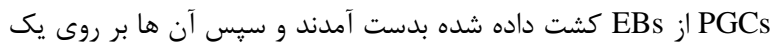

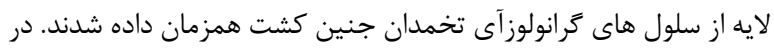

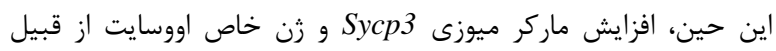

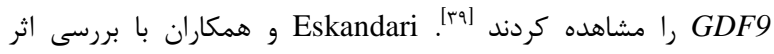

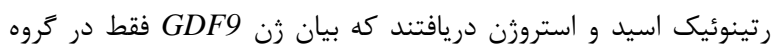

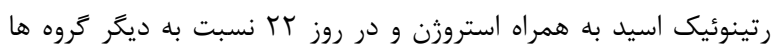

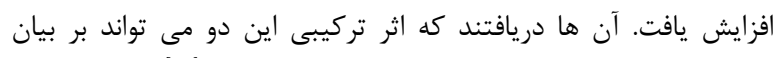

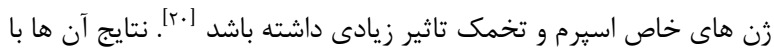

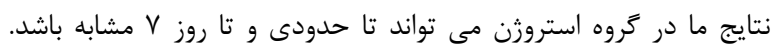

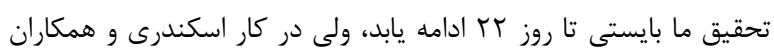

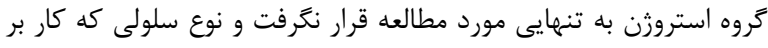
روى آن انجام شد با سلول ما متفاوت بود.

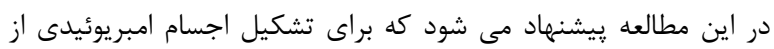

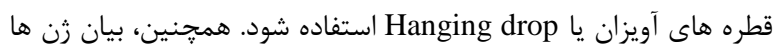

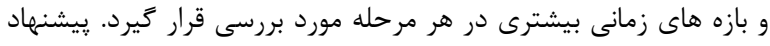

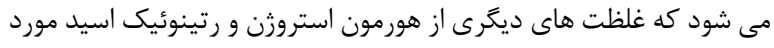

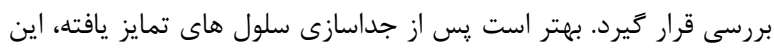

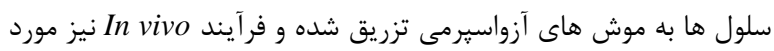
بررسى قرار تيرد.

\section{نتيجه كيرى}

كنترل تمايز iPSCs بسيار سخت است و در شرايط آزمايشگاهى بايد با

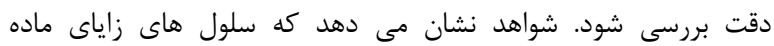

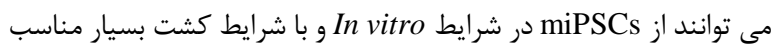

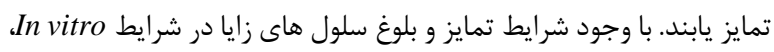

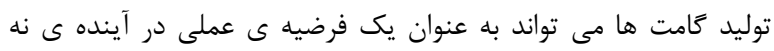

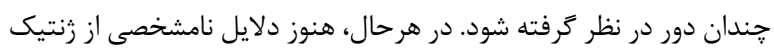

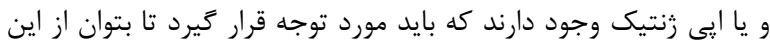

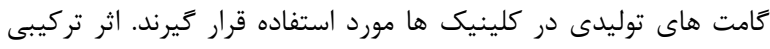

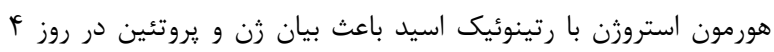

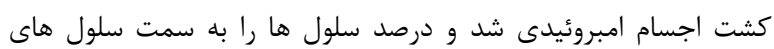

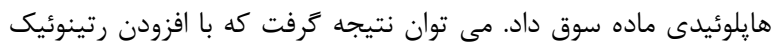

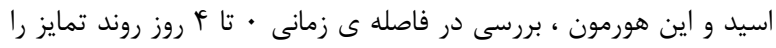
افزايش مى دهد.

$$
\text { تشكر و قدردانى: }
$$

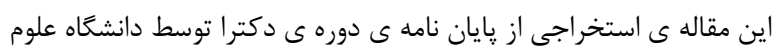

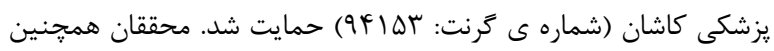

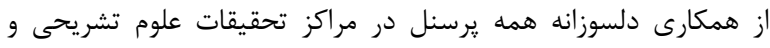

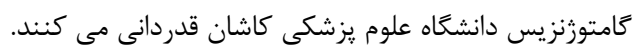


and induced pluripotent stem cells is significantly improved by coculture with human fetal gonadal cells. Stem Cells. 2009;27(4):78395.

15. Hayashi K, Ohta H, Kurimoto K, Aramaki S, Saitou M. Reconstitution of the mouse germ cell specification pathway in culture by pluripotent stem cells. Cell. 2011;146(4):519-32.

16. Mahabadi JA, Sabzalipoor H, Kehtari M, Enderami SE, Soleimani M, Nikzad H. Derivation of male germ cells from induced pluripotent stem cells by inducers: A review. Cytotherapy. 2018;20(3):279-90.

17. Rhinn $M$, Dollé P. Retinoic acid signalling during development. Development. 2012;139(5):843-58.

18. La Sala G, Farini D, De Felici M. Rapid estrogen signalling in mouse primordial germ cells. Exp Cell Res. 2010;316(10):1716-27.

19. Lahmy R, Soleimani M, Sanati MH, Behmanesh M, Kouhkan F, Mobarra N. MiRNA375 promotes beta pancreatic differentiation in human induced pluripotent stem (hiPS) cells. Mol Biol Rep. 2014;41(4):2055-66.

20. Eskandari N, Moghaddam MH, Atlasi MA, Mahabadi JA, Taherian A, Nikzad H. The combination of retinoic acid and estrogen can increase germ cells genes expression in mouse embryonic stem cells derived primordial germ cells. Biologicals. 2018;56:39-44.

21. Mahabadi JA, Sabzalipour H, Bafrani HH, Gheibi Hayat SM, Nikzad H. Application of induced pluripotent stem cell and embryonic stem cell technology to the study of male infertility. J Cell Physiol. 2018;233(11):8441-9. 22. Yang S, Yuan Q, Niu M, Hou J, Zhu Z, Sun $M$, et al. BMP4 promotes mouse iPS cell differentiation to male germ cells via $\operatorname{Smad} 1 / 5$, Gata4, Id1 and Id2. Reproduction. 2017;153(2):211-20.

23. Mi Y, He B, Li J, Zhang C. Progesterone regulates chicken embryonic germ cell meiotic initiation independent of retinoic acid signaling. Theriogenology. 2014;82(2):195-203.

24. Griswold MD, Hogarth CA, Bowles J, Koopman P. Initiating meiosis: the case for retinoic acid. Biol Reprod. 2012;86(2):31-5.

25. Kumar S, Lively B, Liu T, Sun L, Tangpong A, Zhong W. Dramatic effects of scalable snn-assisted melt dispersion on thermal conductivity and coefficient of thermal retinoic acid or testosterone induction. Biomed Res Int. 2013;2013.

5. Hayashi K, Ogushi S, Kurimoto K, Shimamoto S, Ohta H, Saitou M. Offspring from oocytes derived from in vitro primordial germ cell-like cells in mice. Science (80- ). 2012;338(6109):971-5.

6. Tan H, Wang J-J, Cheng S-F, Ge W, Sun $\mathrm{Y}-\mathrm{C}$, Sun X-F, et al. Retinoic acid promotes the proliferation of primordial germ cell-like cells differentiated from mouse skin-derived stem cells in vitro. Theriogenology. 2016;85(3):40818.

7. Ge W, Ma H-G, Cheng S-F, Sun Y-C, Sun L-L, Sun X-F, et al. Differentiation of early germ cells from human skin-derived stem cells without exogenous gene integration. Sci Rep. 2015;5(1):1-9.

8. Dong G, Shang Z, Liu L, Liu C, Ge Y, Wang $Q$, et al. Retinoic acid combined with spermatogonial stem cell conditions facilitate the generation of mouse germ-like cells. Biosci Rep. 2017;37(2).

9. Hübner K, Fuhrmann G, Christenson LK, Kehler J, Reinbold R, De La Fuente R, et al. Derivation of oocytes from mouse embryonic stem cells. Science (80- ). 2003;300(5623):1251-6.

10. Nayernia K, Nolte J, Michelmann HW, Lee JH, Rathsack K, Drusenheimer N, et al. In vitro-differentiated embryonic stem cells give rise to male gametes that can generate offspring mice. Dev Cell. 2006;11(1):125-32.

11. Takahashi K, Yamanaka S. Induction of pluripotent stem cells from mouse embryonic and adult fibroblast cultures by defined factors. Cell. 2006;126(4):663-76.

12. Amini Mahabadi J, Karimian M, Aghighi F, Enderami SE, Seyyed Hosseini E, Talaei SA, et al. Retinoic acid and $17 \beta$-estradiol improve male germ cell differentiation from mouse-induced pluripotent stem cells. Andrologia. 2020;52(2):e13466.

13. Imamura M, Aoi T, Tokumasu A, Mise $\mathrm{N}$, Abe $\mathrm{K}$, Yamanaka $\mathrm{S}$, et al. Induction of primordial germ cells from mouse induced pluripotent stem cells derived from adult hepatocytes. Mol Reprod Dev. 2010;77(9):80211.

14. Park TS, Galic Z, Conway AE, Lindgren A, Van Handel BJ, Magnusson M, et al. Derivation of primordial germ cells from human embryonic 
growth/differentiation factor-9. Mol Endocrinol. 1995;9(1):131-6.

37. Levine AJ, Brivanlou AH. GDF3, a BMP inhibitor, regulates cell fate in stem cells and early embryos. Development. 2006;133(2):209-16.

38. Linher K, Dyce P, Li J. Primordial germ cell-like cells differentiated in vitro from skinderived stem cells. PLoS One. 2009;4(12):e8263.

39. Qing T, Shi Y, Qin H, Ye X, Wei W, Liu H, et al. Induction of oocyte-like cells from mouse embryonic stem cells by co-culture with ovarian granulosa cells. Differentiation. 2007;75(10):902-11. expansion of nanocomposites. Macromol Mater Eng. 2011;296(2):151-8.

26. Geijsen N, Horoschak M, Kim K, Gribnau J, Eggan K, Daley GQ. Derivation of embryonic germ cells and male gametes from embryonic stem cells. Nature. 2004;427(6970):148-54.

27. Makoolati Z, Movahedin M, Forouzandeh-Moghadam M. In vitro germ cell differentiation from embryonic stem cells of mice: induction control by BMP4 signalling. Biosci Rep. 2016;36(6).

28. Panula S, Medrano J V, Kee K, Bergström R, Nguyen HN, Byers B, et al. Human germ cell differentiation from fetal-and adultderived induced pluripotent stem cells. Hum Mol Genet. 2011;20(4):752-62.

29. Yang S, Bo J, Hu H, Guo X, Tian R, Sun C, et al. Derivation of male germ cells from induced pluripotent stem cells in vitro and in reconstituted seminiferous tubules. Cell Prolif. 2012;45(2):91-100.

30. Xuemei L, Jing Y, Bei X, Juan H, Xinling $\mathrm{R}$, Qun L, et al. Retinoic acid improve germ cell differentiation from human embryonic stem cells. Iran J Reprod Med. 2013;11(11):905.

31. Silva C, Wood JR, Salvador L, Zhang Z, Kostetskii I, Williams CJ, et al. Expression profile of male germ cell-associated genes in mouse embryonic stem cell cultures treated with alltrans retinoic acid and testosterone. Mol Reprod Dev Inc Gamete Res. 2009;76(1):11-21.

32. Saiti D, Lacham-Kaplan O. Mouse Germ Cell Development in-vivo and in-vitro. Biomark Insights. 2007;2:117727190700200030.

33. Wongtrakoongate $\mathrm{P}$, Jones M, Gokhale PJ, Andrews PW. STELLA facilitates differentiation of germ cell and endodermal lineages of human embryonic stem cells. PLoS One. 2013;8(2):e56893.

34. Eguizabal C, Shovlin TC, Durcova-Hills G, Surani A, McLaren A. Generation of primordial germ cells from pluripotent stem cells. Differentiation. 2009;78(2-3):116-23.

35. Wang H, Xiang J, Zhang W, Li J, Wei Q, Zhong $\mathrm{L}$, et al. Induction of germ cell-like cells from porcine induced pluripotent stem cells. Sci Rep. 2016;6(1):1-13.

36. McGrath SA, Esquela AF, Lee S-J. Oocyte-specific expression of 